\title{
As Políticas Públicas para Promover e Implementar os Direitos Fundamentais no Trabalho e a Integração Econômica Internacional
}

\author{
M aria C ristina M attioli*
}

Resumo: Avulnerabilidade das economias nacionais e eventos e políticasinternacionaistem criado dilemas e dificuldades no gerenciamento da política nacional ena cooperação internacional. Ao mesmo tempo em que se busca a integração econômica entre as nações, buscando eliminar as diferenças econômicas, surge como limitação desta autonomia nacional, verificando-se, pois, verdadeira tensão. Esta tensão éclaramente sentida no mercado de trabalho, quando da implementação e execução de direitos fundamentais do trabalho, reconhecidos internacionalmente através da Declaração de 1988 da Organização Internacional do Trabalho. A conclusão é que tais políticas só podem ser implementadas através do fortalecimento de regimes intemacionais, como a OIT - Organização Internacional do Trabalho ou a OMC - Organização Mundial do Comércio, com a estipulação de que os países signatários de tratados e convenções relevantes sejam responsáveis por sua implementação, no âmbito nacional. Isto, certamente, representa a derrogação da autonomia nacional em face do movimento global, como resultado de uma regulação harmonizada e que depende de execução intemacional, através de cláusulas sociais inseridas nos acordos de comércio internacional.

Palavras-Chave: Integração Econômica, Hamonização Tributária, Cooperação Intemacional, PolíticasPúblicas

Abstract: The vulnerability of national economies to events and intemational policies has created dilemmas and difficultiesin managing national policiesandintemational cooperation. At thesametimethatnationslook for economic integration, they speak political autonomy. The increasing economic integration among nations, seeking for the elimination of economic differences, emerges as a limitation of this national autonomy, resulting, insofar, in tension. Thistension is clearly seen at the labor market, at the time of implementation and enforcement of fundamental labor rights, asintemationallyrecogmizesby theILODeclaration of 1998. Theemerging conclusion isthatpoliciescan onlybe implemented through the strengthening of intemational organizations, such as the ILO and the WTO, stipulating that theirmember statesberesponsiblefor theimplementation of thosepoliciesara national level. Certainly, thisattitudecan be seen as a representation of national autonomy derogation in face of global movements, as a result of a hamonized regulation depending on intemational enforcement, through sociasclauses, includedin intemational tradeagreements.

Keywords: Economic Integration, Tributary Harmonization, International Cooperation, Public Politics.

*Júza Titular da 4 a Vara do Trabalho de Baun; Professora-Pesquisadora do Centro de Pós-Graduação e Pesquisas da Universidadedo Sagrado Coracãa. E-mail: mattioli.blv@ terra.com.br 


\section{Introdução}

\subsection{Integração econômica e políticas nacionais.}

A interdependência econômica entre as nações aumentou consideravelmente na segunda metade do século passado emuito tem contribuído para a melhoria do padrão de vida em vários países. Todavia, a vulnerabilidade das economias nacionais a eventos e políticas internacionais tem criado dilemas e dificuldades no gerenciamento da política nacional e da cooperação internacional. Ao mesmo tempo em que se busca a integração econômica, as nações buscam sua autonomia política. A crescenteintegração econômica entre as nações, buscando eliminar as diferenças econômicas, surge como limitação desta autonomia nacional, verificando-se, pois, verdadeira tensão.

Esta tensão é aparente em termos de mercado de trabalho, na medida em que se busca uma padronização internacional dos direitos que regem as relações de trabaIho, porém, estimula-se a sua promoção e implementação através de políticas nacionais. Esta padronização, vista como outra face da integração econômica - o trabal ho é outra variante do custo do produto, junto com o capital - força os governos locais a adotarem políticas domésticas compatíveis com a exigência do mercado internacional mas que, na visão de muitos, configuraria protecionismo.

A estreita relação entreas economias deve-se, basicamente, a dois fatores: às transformações tecnológicas, sociais e culturais e à redução das barreiras econômicas através de políticas governamentais. Esta última foi facilitada pela primeira, que colaborou na promoção de novas formas de concretização de tran sações comerciais, impondo a alteração legislativa nacional, inclusive. Em especial, após a Segunda Guerra Mundial, muitos governosnacionais começaram a reduzir suas barreiras comerciais, tornando suas economias mais permeáveis. Asnegociações multilateriais sob os auspícios do GAT T - General Agrement on Trade and Tariffs - desde a Rodada Kennedy na década de 60, a Rodada Tóquio nos anos 70 e, mais recentemente, a RodadaU ruguai - emergem como exemplo mais proeminente de redução de barreiras para o comércio internacional.

Juntos, estes dois fatores contribuíram para a transformação da economia mundial. Simultaneamentea esta realidade, outras transformações ocorreram na estruturapolítica mundial. Primeiramente, a expansão do nacionalismo, através de decisões governamentais, favoreceu a formação de estados independentes ${ }^{1}$ e, posteriormente,

\footnotetext{
1 "The history of membership in international organizations documents the sharp growth in the number of independent states. For example, only 44 nations participated in the Bretton Woods conference of July 1944, which gave birth to the International Monetary Fund. But by the end of 1970, the IMF had 118 member nations. The number of members grew to 150 by the mid-1980s and to 178 by December 1993". (Ehrenberg 1994).
} 
a perda gradual da hegemonia política e econômica dos Estados U nidos, que cedeu lugar, entre outros, a U nião Européia, na medida em que as relações passaram a ser demultilateralismo, ao invés do bipolarismo existente atéentão, em razão da Guerra Fria, Estados Unidos-U nião Soviética. Ainda, pode-se acrescentar a transformação política e econômica dos países do Leste-Europeu que adotaram reformas com base nos princípios capital istas ocidentais. Estes fatores são essenciais na análise dos dilemas das políticas nacionais posto que, quanto maior a integração euniformização de mercados, menor o poder de resistência dos estados nacionais.

A separação entre política internacional e nacional era claramente visualizada. 0 cidadão sabia que, em regra, a primeira restringia-se às tarifas e cotas do comércio internacional eà segunda, era destinada às regulações da concorrência, sociedades, padrões de produção, segurança no trabal ho, instituições financeiras, proteção ambiental, entretantos assuntos. Todavia, à medida em que as barreiras foram diminuindo e as inovações tecnológicas ocorrendo, as distâncias econômicas encolheram ea política nacional ficou mais exposta às exigências internacionais. Assim, governos nacionais enegociações internacionais tiveram que lidar, cada vez de forma mais aprofundada, com a integração de políticas. Por exemplo, se um país $A$ permite que uma companhia utilize-se de trabalho forçado na produção de um bem e outro país $B$ não permite, gerando este país $A$, um custo mais baixo do produto, as companhias no país $A$, que competem internacionalmente com as companhias do país $B$, estarão se ben eficiando de uma prática desleal no comércio e pressionarão pela elevação dos padrões de trabalho.

Assim, se se pretende a elaboração de uma política nacional de promoção do crescimento econômico e desenvolvimento social, deve-se levar em consideração a tensão que exsurge com o aprofundamento da integração econômica das nações, levando à diminuição da autonomia nacional e desafiando a soberania política². Este é, pois, 0 foco do presentetrabal ho: apresentar atensão existenteentrea necessidade de integração econômica e a perda de autonomia nacional em face do movimento, cada vez maior, por padronização depolíticase direitos, constituindo uma harmonização de regulações. N este sentido, a implementação de direitos fundamentais no trabal ho deve ser vista à luz desta tensão, eis que políticas públicas nacionais vão levar em consideração a grande variedade de normas internacionais ratificadas.

\footnotetext{
${ }^{2}$ Como sustentam Montgomery e Glazer, ao discomerem sobre o que chamam de "globalismo", "... there are newlyrecognized moral claims on the state that have displaced the head of govemment as its sole appropriate or legitimate source of sovereignty. It is no longer considered fanciful to argue that the ultimate rationale for sovereignty is derived from the obligation to pursuea state'smoral purposesrather than theright to guaranteeitspower, to protectitsteritorial integrity, or to advance the material interests of its citizens". (Montgomery eGlazer 2002: 04).
} 
A conclusão éque tais políticas só podem ser implementadas através do fortalecimento de regimes internacionais, como a O IT - O rganização Internacional do Trabalho ou a O M C - O rganização M undial do Comércio, com a estipulação de que os países signatários de tratados e convenções relevantes sejam responsáveis por sua implementação, no âmbito nacional. Isto, certamente, representa a derrogação da autonomia nacional em face do movimento global, como resultado de uma regulação harmonizada e que depende de execução internacional, através, como se sustentará, de cláusulas sociais inseridas nos acordos de comércio internacional.

\section{A tensão entre políticas internacionais e nacionais e o mercado de trabalho}

Algumas atividades nacionais produzem conseqüências queatravessam fronteirase afetam outras nações. Isto acontece, por exemplo, com as instituições financeiras, através do impacto da moderna tecnologia, que permite transações internacionais instantâneas e, muitas vezes, fraudulentas. 0 mesmo ocorre com as políticas no mercado de trabalho. Políticas de trabal ho tornam-se objeto de consideração por outros países, em função da imigração de trabal hadores que buscam trabalho em outro contexto. Assim, políticas de um país podem atingir o fluxo imigratório, aumentando ou diminuindo 0 mercado de trabalho. N este sentido, a tensão existente entre a pressão internacional para liberação da mobilidade da mão-de-obra e a política doméstica de proteção do mercado de trabalho nacional, pode gerar resultados passíveis de serem vistos como concorrência desigual. Basicamente, o país que sofre as conseqüências desta política, pressiona para que as restrições sejam eliminadas. N este ponto, as tensões aumentam entre as nações. Q uando, por exemplo, governos nacionais negociam resoluções para questões como esta, que refletem no mercado de trabalho - tentando acordar sobre a legitimidade do país em efetivar suas escol has políticas e o dano que possa ser causado em outras nações - o diálogo é, invariavelmente, polêmico, eis que as resoluções dependem de circunstâncias complexas do cenário internacional e do peso do interesse particular de cada indivíduo ou nação (M ontgomery e G lazer 2002: 1).

Esta polêmica diminui a autonomia nacional, na medida em que o estado, individualmente, tem que cooperar com a exigência internacional do mercado, alterando seu regime legal, padrões e instituições, muitas vezes em atendimento a valores universais ou internacionais. O utras vezes, o próprio estado, através de seus cidadãos, pressiona para esta modificação.

Alguns gruposconcentram-senosdireitoshumanos, por exemplo, epressionam para a universalização de direitos trabalhistas considerados fundamentais e também humanos. 0 movimento para esta padronização éinternacional, mas, ao mesmo tempo, polí- 
ticas nacionais colidem com estesinteresses. U m caso recentefoi a proi bição detransação comercial imposta, pelosEstados U nidos, às empresas que negociavam com o Estado de M yanmar (Burma), devido ao uso do trabalho forçado. 0 u ainda, a manifestação dos pescadoresamericanos, que reclamaram acerca da importação de atum de países quenão utilizavam as mesmas regras de pesca equeafetaram o M éxico eaVenezuela, em razão da proibição de importação por não atender aos padrões da comunidade ambientalista.

D esta forma, há necessidade de se estabelecer uma política de convergência internacional, mas que respeite a autonomia nacional, objetivando uma explícita harmonização de padrões regionais ou globais.

Considerando-se que o mercado de trabalho possui uma série de características que influencia o fluxo comercial, tanto de capital como de mão-de-obra, ele vai ser influenciado, também, pelo processo de integração econômica, que pressiona por mudanças. Todavia, apesar das tensões, é perfeitamente possível que a integração econômica sobreviva entre países com diferentes níveis de padrões e políticas de trabalho. A tensão existe, mas pode ser atenuada através de políticas domésticas convergentes com a necessidade de ajuste da política econômica ao comércio internacional ${ }^{3}$.

\section{O Mercado de trabalho}

0 mercado de trabalho e a relação de emprego envolvem muito mais fatores do que a simples troca da prestação de serviços pelo salário. Jornadas de trabal ho, por exemplo, são, freqüentemente, objeto de legislação nacional ou negociação coletiva e estão influenciadas por outros fatores públicos, como feriados, férias, políticas de fixação de horários para o comércio, setor bancário, industrial. Seja através de legislação ou através do processo da negociação coletiva, muitos países estabelecem os seus próprios padrões para o mercado de trabalho a fim de garantir aos trabalhadores condições minimamente desejáveis de trabal ho. Estes padrões incluem: salário mínimo, restrições ao trabalho infantil, saúde ocupacional esegurançano trabalho, políticas não-discriminatórias em razão de gênero, raça, idade ou deficiência, por exemplo. Assim é que muitos países possuem políticas que facilitam o ajuste do mercado de tra balho, incluindo quem pode ingressar no país (políticas de imigração) e quais os direitos quevão determinar o contexto do trabal hador (direitosfundamentaisno trabal ho). M uitos

\footnotetext{
${ }^{3}$ Esta tensão é bem retratada por Ronnie Lipschutz ao analisar a regulação e a política social separadamente e sob as condições da globalização. Para o autor, de um lado, tem havido grandes modificações na divisão internacional do trabalho associadas aos veículos de mercadoria transnacional, e, ao mesmo tempo, têm sido feitas mudanças nos regimes internacionais, mercados e estados. (Lipschutz 2002: 292).
} 
críticos da liberalização do comércio acreditam que seja injusto celebrar acordos comerciais com países que possuem padrões de trabal ho muito inferiores ou quenão exigem o cumprimento dospadrõesjá existentes. N estecontexto, valelembrar o debatequando da implantação do N AFTA - N orth America FreeTradeArea em 1993, tendo seusopositores argüido que o tratado não poderia ser assinado a menos que um acordo em anexo fosse firmado, para garantir que o M éxico atendesse a condições mínimas de trabalho, entre elas, salário mínimo, legislação proibindo o trabalho infantil e protegendo a saúde e segurança do trabal hador ${ }^{4}$. Estes padrões, à toda evidência, fazem com que existam modificações na política de trabalho, com base, precipuamente, na política econômica. Isto porque, normalmente, tais padrões impõem custos para os empregadores que não podem ser realocados para o trabal hador ${ }^{5}$.

D esta forma, as características do mercado de trabal ho e de suas instituições são diretamente afetadas pela integração econômica e vice-versa. Porém, observa-se que esta integração, não necessariamente, exige a harmonização dos padrões de trabal ho nacionais, como salário mínimo, jornada de trabal ho ou seguros para os desempregados. Todavia, quanto maior aintegração econômica, mais sepressiona para que direitos considerados fundamentais sejam observados, não só porque influenciam, diretamente, os custos da produção, mas, principalmente, porque fazem parte de um leque maior, que são os direitos humanos universais. A fixação destes direitos mínimos, contudo, em termos de legislação, pouco significado tem se não houver políticas nacionais para sua implementação e posterior compromisso de torná-los eficazes e executados, seja através da legislação nacional ou através das sanções comerciais impostas através de acordos comerciais internacionais.

\section{Direitos Fundamentais no Trabalho}

\subsection{O vínculo trabalho-comércio}

D e uma forma geral, as escolhas políticas definem o modelo econômico a ser seguido nacionalmente. Em conseqüência, devido à forte influência das empresas e

\footnotetext{
${ }^{4}$ A administração Clinton negociou tal acordo em agosto de 1993, conforme: "HOW Complaints Would Be Handled", In New York Times, 14 de agosto de 1993, p. 45.

${ }^{5}$ Salário mínimo aumenta 0 custo para a maioria dos empregadores que se utilizam de mão-de-obra nãoqualificada no processo de produção; leis que dispõem sobre 0 trabalho infantil e sobre 0 trabalho forçado também aumentam os custos para o mesmo grupo de empregadores; igualmente há aumento do custo quando 0 trabalho da mulher passa a ter a mesma remuneração que 0 trabalho masculino.
} 
do comércio internacional, é evidente, que estemodelo tem o poder deinfluenciar a ordem jurídica. $\mathrm{N} o$ âmbito das relações do trabalho, este atual modelo - que privilegia a liberalização do comércio - é responsável por formatar um novo modelo de relações laborais. Por conseguinte, dele decorre a necessidade de regulamentação particular, dando origem, também, a um novo ordenamento jurídico laboral.

$N$ a medida em queestas relações estão presentes econsolidadas, cada vez mais secomprova quetrabal ho ecomércio são elementosinseparáveis. M uita discussão acadêmica exis te acerca deste vínculo e a forma como ele se concretiza. A tentativa de elaboração deste vínculo podeser transportadaparadesdequando o Japão obteveacesso alTO (International TradeO rganization), predecessorado GATT/WTO (General Agreement on TradeandTariffs) World TradeO rganization), durantea década de 50, atéo final do milênio, quando aChina tornou-semembro desta organização internacional. A especulação acerca da existência deste vínculo varia entre dois eixos: política salarial edireitos humanos.

O sistemaderegulação do comércio internacional foi desenhado parausar o salário como a exata medida para determinar a violação de padrões de trabalho, os quais, por sua vez, têm evidenteimpacto nos custos da produção. E, sem dúvida, o valor do salário éelemento chave no custo. Este foi o principal argumento dos ingleses ao oporem-se à adesão do Japão ao G ATT. O sbaixos salários dostrabalhadores japoneseseram vistos como umavantagem comparativa desleal também pelos americanos, o que poderia préudicar as relações comerciais. O utras questões também foram levantadas, como a não observância das leis sobre condições e jornada de trabalho, além do desrespeito à liberdade de associação e negociação coletiva. Tanto isto é verdade, que o Secretário-Executivo do GATT respondeu a tais considerações inglesaseamericanas, dizendo queo governo japonêshaviafeito provadenão maisretornar ao sistema de mão-de-obra barata, tendo modificado sua legislação proibindo práticas injustas no trabalho. N ão obstanteestasmedidas, o medo sempreestevepresentenos paísesopositores, mas, dequalquer forma, o Japão tornou-se membro em $1955^{\circ}$.

Como se percebe, claramente, a política salarial, quer dizer, o salário, principal elemento das relações industriais e reflexo do modelo econômico, teve participação importante na vinculação do trabal ho ao comércio. No entanto, esta orientação foi,

\footnotetext{
${ }^{6}$ Como pontificado por Elissa Alben, "In sum, during Japan's accession process, the negotiators focused on production cost to generate stop-gap trade measures, including an enhanced safeguards deal and an Article XXIII plan, to prevent theinflux of lower cost goods produced with lower labor standards. Their approach naturally comported with an understanding of labor standards as having an impact on wages. In fact, all proposals offered (other than the opt-out solution of Article XXXV) relied upon provisions that explicitly required a showing of injury, and hence some production cost effect”. (Alben 2001 - 101 Colum. L.Rev. 1410).
} 
mais recentemente, alterada, com o ingresso da China na $\mathrm{OM} \mathrm{C}$, onde outro aspecto da questão foi levantado: a vinculação também com os direitoshumanos. N a opinião deRaj Bhala, esta vinculação trabal ho e comércio enseja duas questões eassim semanifesta: "the economic cornerstones of the trade-labor link are wages and employment. The political cornerstone is the outrage against exploitation of workers rights" ${ }^{\prime 2}$.

Assim éque, quando a China pretendeu sua inclusão no GAT T /W TO , ao contrário do Japão, não se questionou a prática de mão-de-obra barata em razão da inobservância de condições detrabalho, porém, em razão de violações dedireitos trabalhistasfundamentais, considerados como direitoshumanos, isto é, o uso da mão-de-obra infantil, por exemplo ${ }^{8}$. N esta esteira, o debate sobre como os padrões de trabalho devem ser entendidosno contexto do comércio, teve seu rumo al terado. 0 desenvolvimento na área de direitos humanos internacionais, em especial no pós-guerra ${ }^{9}$, teve um papel importante na crescente ênfase dada aos direitos trabal histas como direitos humanos. 0 acesso de países menos desenvolvidos ao GATT/WTO intensifica este debate, na medida em que o salário, nestes países, évisto como uma vantagem comparativa $^{10} . \mathrm{E}$, assim, a linguagem dos direitos humanos serve como importante retórica na tentativa de remover, deste debate, a discussão pautada na política salarial ${ }^{11}$.

\footnotetext{
${ }_{7}^{7}$ Canifying the Link. Columbia Journal of Transnational Law. Vl. 37, 1998 (37 Colum.J.Transnatl L 11, 19 (1998)). 8 "Certainly, another clear contrast is the extent to which human rights principles, rather than wages, have been invoked in the labor standards debate over China's accession". Idem 6.

${ }^{9}$ "Atter the Second World War, and especially in the last one or two decades, as the process of globalization gathered momentum andlaborand capital, began to movemorefreelyacrossnations, thelabor standards concem spilledbeyond national and regional boundariesand becamepropenly an intemational matter". (Basu 2001 - 34 Comell Int'l LJ. 487). ${ }^{10} \mathrm{Na}$ verdade, os países em desenvolvimento acreditam que a inclusão destes direitos básicos na $\mathrm{OMC}$ vão diminuir sua vantagem comparativa, quando se trata de salários, o que não é verdadeiro, uma vez que a questão de estabelecimento de salário mínimo global foi deixada de fora do leque de direitos fundamentais.

${ }^{11}$ A propósito, bastante esclarecedora esta anotação do Professor William Gould, ao tratar da históna dos padrões intemacionais do trabalho, também traçando esta vertente, entrepolítica salarial edireitos humanos; assim semanifesta: "The idea of intemational labor standards first gained momentum in early Nineteenth Century Great Britain with Robert Owen as their proponent- and It was catalyzed by the expansion of the antislavery movement. Advocacy for this idea found strength in France, Switzerlandand Germany, and proponentsclaimed thatbasichuman rightswereinvolved inasmuch as the benefits had their source in morality. But then as now, an argument for uniformity across nations, which can overidethenation state'ssovereignty, wasputforward on thegrounds thatnationsproviding improved wages and benefitswould otherwiselosetheircompetitive position. Thus, advocacy flourished, and continuesto flourish, in the richer countries. Yet it is an argument that arises in the context of advanced countries competing amongst themselves when the question of comparative advantage enjoyed by developing countries, existing at a different economic state of development, isunknown". (Gould IV2001 - 80 Neb. L Rev. 715).
} 
Esta aproximação de trabalho e comércio implica, não só esta análise econômica e política, mas também uma análise no âmbito da concretização. Em outras palavras, se existe este vínculo, a questão que se coloca é como el e pode ser representado no mundo jurídico. Muitas medidas foram apresentadas - como o selo social, as declarações de direitos e princípios, os sistemas de preferência nos Estados U nidose Europa- masnenhuma outra teve, eainda tem, tanta repercussão como a denominada "cláusula social", no sentido de ser uma ação supranacional com o intuito de impor sanções comerciais àquel es países que descumprem os direitos fundamentais no trabaIho, internacionalmente fixados. $E$, neste sentido, a primeira questão que surge diz respeito ao conteúdo desta fixação.

\subsection{A Declaração de 1998 da OIT}

Podese dizer que existem duas formas de fixação coletiva destes direitos mínimos, fundamentaiseinternacionais do trabal ho: osdireitosfixados pelasempresastransnacionais, através de seus códigos de conduta ou através das normas que incorporam quando da adesão ao G lobal Compact, Programa das N ações U nidas, com o objetivo de fixar direitos e impor uma responsabilidade social para as empresas; e, os direitos e deveres impostos aos governos, através das convenções e recomendações da O rganização Internacional do Trabalho. Estes instrumentos são referências essenciais dentro deste contexto ${ }^{12}$.

A globalização destas referências levaram a uma codificação de padrões. Basicamente, foram eles classificados em quatro espécies de direitos: 1) direitos básicos, que incluem o direito contra a prestação de serviços involuntária emedidas contra 0 trabal ho infantil ea discriminação; 2) direitos civis, aqui incluído o direito do trabalhador de livremente associar-se e negociar coletivamente; 3) direitos de sobrevivência, abrangendo 0 direito a um salário mínimo, indenização por acidente e direito a não ser exposto ao perigo; 4) direitos de segurança, impondo restrições às demissões e outorgando direitos a pensões por aposentadoria.

Esta padronização está presente em vários documentos internacionais ${ }^{13} \mathrm{e}$, de uma forma geral, todos se concentram em cinco condutas: 1) proibição do trabalho forçado; 2) proibição de discriminação no emprego; 3) direito de associação; 4) direito à negociação coletiva; e, 5) proibição do trabalho infantil.

\footnotetext{
${ }^{12}$ "Theimportant difference between these two voluntary schemes is that they place the primary responsibility of ILS on different agencies. The Global Compact places the responsibility on multinationals and big corporations while theILO conventionsplace the responsibility on thenations, and primarily the Third World nations since theseare the potential violators of the standards". Idem 11.
} 
Verifica-se destas condutas e dos documentos quea contêm, um crescente consenso internacional sustentando que os chamados "direitos trabal histas fundamentais" são também direitos humanos fundamentais ${ }^{14}$. Em 1998, a O rganização Internacional do Trabalho aprovou a D eclaração de Princípi os e D ireitosFundamentais no Trabalho eSeu Seguimento ${ }^{15}$, a qual proclama quatro princípios básicos, extraídos de suas convenções e aplicáveis a todas as nações, independentemente de seu nível de desenvolvimento econômico, e que colidem com os direitos supra-mencionados, quais sejam:

- liberdade de associação e de organização sindical e ao reconhecimento efetivo do direito de negociação coletiva

- eliminação de todas as formas de trabalho forçado ou obrigatório

- abolição efetiva do trabalho infantil

- eliminação da discriminação em matéria de emprego e ocupação.

Esta D eclaração aplica-se a todos os membros da O IT, independentemente da ratificação das oito convenções fundamentais que correspondem a estes princípios, que são: C onvenção $29^{16}$ (Trabalho Forçado); Convenção $87^{17}$ (Liberdade Sindical);

\footnotetext{
${ }^{13}$ A OECD elaborou um estudo em 1996 (atualizado em 2000) sobre 0 elenco destes padrões e o porquê desta distinção. Como salienta o Professor William Gould IV, op. cit, "TheOECD emphasizesits concem about uniformity by its distinction between core labor standards and other labor standards. The OECD finds this distinction to be "crucial" inasmuch as working time and minimum wages can affect "patterns of comparative advantage, e.g., higher minimum wagesarelikely to affect trade performancenegatively. But corelabor standards, unlikeminimum wages, will not necessarily affect comparative advantage negatively, and indeed may have a positive effect."

${ }^{14}$ Apesar de algumas diferenças, os princípios contidos nos instrumentos da OIT são considerados " quase completamente consistentes" com vários textos das Nações Unidas, como 0 Artigo 23 (4) da Declaração Universal de Direitos Humanos e 0 Artigo 22 da Convenção Internacional sobre Direitos Civis e Políticos e Artigo 8 da Convencão Internacional sobre Direitos Econômicos, Sociais e Culturais.

${ }^{15}$ Oprograma In-Focus "Promoção da Declaração" inclui atividades de seguimento dos compromissos assumidos pelos Estados Membros da OIT, incluindo relatórios anuais dos Estados Membros que ainda não ratificaram alguma das oito Convenções, e relatórios globais sobre o progresso alcançado em nível mundial em cada uma das quatro áreas de princípios e direitos fundamentais.

${ }^{16}$ Trabalho forçado (1930): dispõe sobre a eliminação do trabalho forçado ou obrigatório em todas as suas formas. Admitem-se algumas exceções, tais como 0 serviço militar, 0 trabalho penitenciário adequadamente supervisionado e 0 trabalho obrigatório em situações de emergência, como guerras, incêndios, terremotos, etc. ${ }^{17}$ Liberdadesindical eproteção do direito desindicalização( (1948): estabelece o direito detodos os trabalhadores eempreyadoresdeconstituirorganizações que considerem convenientesedea elasseafiliarem, sem prévia autorização, edispõesobre uma séne de garantias para o livefuncionamento dessas organizações, sem ingerência das autoridades públicas.
} 
Convenção $98^{18}$ (D ireito deSindicalização eN egociação Coletiva); Convenção $100^{19}$ (I gualdade de Remuneração); Convenção $105^{20}$ (Abolição do Trabalho Forçado); Convenção $111^{21}$ (D iscriminação no Emprego); Convenção $138^{22}$ (Idade M ínima para o Trabalho); Convenção $182^{23}$ (Piores Formas de Trabalho Infantil).

Reconhecendo a importância destes direitos e princípios fundamentais, a O IT adotou a declaração, a qual impõeuma obrigação para os estados-membrosem respeitála deboa-fée deacordo com sua C onstituição. 0 desenvolvimento desterol dedireitos implica que esforços especiais sejam efetivados para garantir que estes e outros direitos reconhecidos nas conven ções sejam aplicados pel os países-membros. Tradicionalmente, a O IT tem tido papel fundamental na elaboração destas convenções, porém, sua atuação tem sido menos efetiva na sua execução. N a prática, a adoção da D eclaração não assegura, automaticamente, que todos os estados-membros vão respeitar suas disposições. A O IT, na verdade, carece de mecanismo efetivo para exigir o cumprimento, pelos seus membros, das suas convenções ou da D eclaração.

N este sentido, embora o conceito de direitos ou padrões fundamentais no trabal ho tenha obtido um consenso, ainda existeum considerável debate em relação à aplicação e execução destes direitos e quais os mecanismos mais apropriados para tanto. A OIT, como visto, através da Declaração de 1998 estabeleceu um mecanismo de promoção ou seguimento e, basicamente, sua atividade está ligada à orientação, assistência técnica e programas para implementação da D eclaração. 0 cumprimento é, no fundo, voluntá-

\footnotetext{
${ }^{18}$ Direito de sindicalização e de negociação coletiva (1949): estipula proteção contra todo ato de discriminação que reduza a liberdade sindical, proteção das organizações de trabalhadores e de empregadores contra atos de ingerência de umas nas outras, e medidas de promoção da negociação coletiva.

${ }^{19}$ Igualdade de remuneração (1951): preconiza a igualdade de remuneração e de benefícios entre homens e mulheres por trabalho de igual valor.

${ }^{20}$ Abolição do trabalho forçado (1957): proíbe o uso de toda forma de trabalho forçado ou obrigatório como meio de coerção ou deeducação política; como castigo por expressão de opiniõespolíticas ou ideológicas; a mobilização demãode-obra; como medida disciplinarno trabalho, punição por participação em greves, ou como medida de discriminação. ${ }^{21}$ Discriminação (emprego e ocupação) (1958): preconiza a formulação de uma política nacional que elimine toda discriminação em matéria de emprego, formação profissional e condições de trabalho por motivos de raça, cor, sexo, religião, opinião política, ascendência nacional ou origem social, epromoção da igualdade de oportunidades e de tratamento.

${ }^{22}$ Idade Mínima (1973): objetiva a abolição do trabalho infantil, ao estipular que a idade mínima de admissão ao emprego não deverá ser inferior à idade de conclusão do ensino obrigatório.

${ }^{23}$ Piores Formas de Trabalho Infantil (1999) : defende a adoção de medidas imediatas e eficazes que garantam a proibição e a eliminação das piores formas de trabalho infantil.
} 
rio, inexistindo sanções em caso de violações. Logo, há necessidade de se discutir qual o melhor caminho equal o órgão apropriado para que tais direitosfundamentais, quando implementados através de políticas nacionais, sejam, efetivamente, cumpridos.

\subsection{A cláusula social em acordos bilaterais e multilaterais do comércio}

Uma das formas de imposição para cumprimento dos direitos fundamentais no trabalho é através da adoção de cláusulas sociais nos acordos de comércio internacional. 0 conteúdo desta cláusula pode consistir dos direitos reconhecidos pela 0 rganização Internacional do Trabalho, através da D eclaração de 1998. A imposição desta cláusula social, estaria vinculada a acordos de comércio internacional esob os auspícios da WTO, que imporia sanções comerciais aos países que a violassem. M uita crítica se fez contra esta proposta e é por esta razão que o tema saiu da esfera de debates dentro da WTO e passou para a OIT, culminando com a Declaração de 1998. Há uma grande preocupação, nos países menos desenvolvidos, que uma medida como esta poderia implicar em protecionismo em relação aos países desenvolvidos ${ }^{24}$.

A té o momento, uma cláusula como esta ainda não figura em contratos comerciais supranacionais, dentro da WTO . Todavia, ela está presente em muitos outros acordos bilaterais, celebrados entre os países, especial mente quando os Estados U nidosé parte ${ }^{25}$, amparado pelo G SP - General System of Preferences, ou ainda nos acor-

\footnotetext{
${ }^{24}$ Comoanota KaushikBasu, "Perhapsthemostpotentform of supra-national action contemplatedisto havea social clause in theWTO provisions, which wouldallow theWTOto impose tradesanctions on an ering country". Ealerta que "Therisk of empowering the WTO thus is that this will becomea powerful instrument of protectionism in the North". Finalmente, exemplifica com um caso brasileiro: "An interesting casein pointistheuseof theSander's Amendmentagainst the Brazilian company Sucocitrico Cutrale. The charge was that the company wasusing children to pluck oranges. However, astheWall StreetJoumal pointed out thiswasprobablyan act of reprisal headed by theTeam sters Union against Cutrale for downsizing someMinute Maid plantsithad boughtfrom Coca-Cola Co in Forida". (Basu 2001).

${ }^{25}$ Por exemplo, o acordo celebrado com a Jordânia, para estabelecimento deárea livre de comércio, assinado em 24 de outubro de 2000 e em vigor desde 17 de dezembro de 2001, cujo artigo $6^{\circ}$ explicitamente dispõe que: ARTICLE 6: LABOR 1. The Parties reaffirm their obligations as members of the Intemational Labor Organization ("ILO") and their commitments under the ILO Declaration on Fundamental Principles and Rights at Work and its Follow-up. The Parties shall strive to ensure that such labor principles and the intemationally recognized labor rights set forth in paragraph 6 are recognized and protected by domestic law.... 3. Recognizing the right of each Party to establish its own domestic labor standards, and to adopt or modify accordinglyitslabor laws and regulations, each Party shall strive to ensure that itslaws provide for labor standards consistent with theintemationally recognized labor rights set forth in paragraph 6 and shall strive to improve those standards in that light... 5. The Parties recognize that cooperation between them provides enhanced opportunities to improve labor standards. The Joint Committee established under Article 15 shall, during its regular sessions, consider any such opportunity identified by a Party. 6 . For purposes of this Article, "labor laws" means statutes and regulations, or provisions thereof, that are directly
} 
dos celebrados com países menos desenvolvidos, no âmbito da União Européia, como autorizado pelo Parlamento Europeu, em 1994, emencionado no documento Resolution on EU standards for European Enterprises operating in developing countriestowards a European $\mathrm{C}$ ode of $\mathrm{C}$ onduct ${ }^{26}$.

A diferença entre 0 sistema dos Estados Unidos e o sistema da U nião Européia consiste em sanções, pelo primeiro, quando violadas tais cláusulas e, em incentivos, pelo segundo, quando cumpridas tais cláusulas. H á de mencionar-se, ainda, que no âmbito da União Européia, as diretrizes emitidas para os países-membros também contêm certo efeito vinculativo, objetivando a padronização mínima de direitos trabaIhistas. D esta forma, a tensão entre a necessidade de integração econômica global e as políticas nacionais de trabal ho, seriam meramente aparentes, posto que estariam conjugadas num único instrumento.

Evidentemente, a questão não está pacificada e muitos países ainda acreditam que a implementação destes direitos fundamentais é um primeiro passo para a harmonização e, a sua efetividade, pode ser dada através de legislação nacional. Tal se dá, por exemplo, no D ireito Americano, através do ATCA - Alien Torts Claim Act, através do qual tem-se responsabilizado empresas americanas que violem direitos trabalhistas fundamentais quando atuando em outros países ${ }^{27}$.

related to the following intemationally recognized labor rights: (a) the right of association; (b) the right to organize and bargain collectively; (c) a prohibition on the use of any form of forced or compulsorylabor; (d) a minimum age for the employment of children; and (e) acceptable conditions of work with respect to minimum wages, hours of work, and occupational safety and health". 0 mesmo ocorreu com 0 acordo celebrado com 0 Camboja, especificamente para 0 setor têxtil, firmado em 12 de janeiro de 1999: "10. (A) The Parties seek to create new employment opportunities and improve living standards and working conditions through an enhanced trading relationship; affirm respect for each Party's legal system and seeking to ensure that labor laws and regulations provide for high quality and productive workplaces; and seek to foster transparency in the administration of labor law, promote compliance with, and effectiveenforcement of, existing labor law, and promote the general labor rights embodied in the Cambodian labor code. (B) The Royal Government of Cambodia shall support theimplementation of a program to improve working conditions in the textile and apparel sector, including intemationally recognized core labor standards, through the application of Cambodian labor law.

(C) The Government of the United States and the Royal Government of Cambodia shall conduct notless than two consultations during each Agreement Year to discusslabor standards, specific benchmarks, and theimplementation of this program". Disponível: http://www.tcc.mac.doc.gov/cgi-bin/doit.cgi?204:64:1:301 e http:// www.tcc.mac.doc.gov/cgi-bin/doit.cgi?204:64:1:25. Acesso: 27/05/03.

${ }^{26}$ ".... having regard to its resolution of 9 February 1994 on the introduction of a social clause in the unilateral and multilateral trading system (OJ C 61,28.2.1994, p. 89.)". 


\section{Elementos para elaboração de política pública}

\subsection{Direitos fundamentais e os desafios da globalização}

$\mathrm{N}$ ão é por demais repetir que, enquanto a economia cresce internacionalmente, integrando mercados, a regulação do mercado de trabal ho continua, largamente, sendo elaborada em níveis nacionais. As instituições do trabalho ainda são produzidas e controladas por autoridadesnacionais, mesmo quese atenda às orientações da 0 rganização Internacional do Trabalho, cuja cooperação é voluntária. N este sentido, pode-se dizer que não há uma legislação internacional do trabalho, no sentido estrito, isto é, elaborada e com autoridade para execução de suas disposições em termos globais.

A pesar desta soberania legal, as nações não são autônomas em termos de escolha da política de trabal ho. A crescente mobilidade do capital e do produto no mercado impõe restrições a esta escolha política. N este sentido, como a adoção de direitos fundamentais impõe, muitas vezes, um custo, os governos relutam em pressionar por padrões mais el evados. Assim, a abertura da economia nacional ea intensa competitividade entre os países, provoca este debate acerca da implementação de direitos fundamentais no trabalho através de políticas públicas nacionais. $N$ a verdade, a grande disparidade entre os custos do trabal ho entre os países impulsionam para a eliminação de práticas consideradas injustas no comércio equepoderiam provocar o dumping social, através do descumprimento de direitos fundamentais no trabalho. N este sentido, com o aumento do comércio internacional edo investimento estrangeiro direto, a vantagem comparativa de alguns países têm diminuído e o custo do trabal ho passa a ser um el emento a mais na redução do custo do produto, detal sorte quea mão-deobra barata possa ser um grande atrativo. Logo, a disparidade no custo do trabalho aumenta a controvérsia internacional.

\footnotetext{
${ }^{27}$ Em 18 de setembro de 2002, o United States Court of Appeals for the Ninth Circuit, considerou a responsabilidadeintemacional subsidiária de empresas americanas em Myanmar, anteriormentechamado Burma. Os autores - John Doee Outros- propuseram ação contra o governo militar de Myanmar, contra a companhia estatal de petróleo e contra companhia de petróleo americana (Government of Myanmar, UNOCAL Corporation e TOTAL S.A) alegando que, direta ou indiretamente, moradores locais foram submetidos a trabalhos forçados, assassinatos, estupros e torturas, durante construção de infra-estrutura petrolífera em Myanmar. Tais atos teriam sido praticados por militares, com conhecimento da empresa. 0 Tribunal entendeu que a responsabilidade pelas violações decorrem do princípio jus cogens e, por consegüinte, implica em violações de Direito Internacional (law of nations). Aresponsabilidade decorre da aplicação do ATCA- Alien Tort Claims Act, um estatuto americano que pode sustentar a responsabilidade internacional de companhias estrangeiras.
} 


\subsection{Execução dos direitos fundamentais no trabalho}

Se, por um lado, a implementação de políticas públicas para introdução de direitos fundamentais no trabalho é uma questão que, apesar do aparente conflito, pode ser resolvida com a cooperação de organismos internacionais, como a O IT, por outro lado, o mecanismo apropriado para executar e tornar estes direitos eficazes é ainda uma questão intrigante para os governos nacionais.

Como se sugere acima, a introdução de cláusulas sociais em acordos de comércio internacional - bilaterais ou multilaterais - é um mecanismo eficaz e que garante 0 efetivo cumprimento e observância dos direitos fundamentais no trabalho. Todavia, outros mecanismos podem ser adotados.

Richard Freeman analisa o comportamento do consumidor no momento da escoIha de um produto e sugere que este seja o referencial para tais mecanismos. Assim, no âmbito doméstico, dois mecanismos estariam disponíveis: a legislação e o sel o social, que funcionaria como um Certificado de Qualidade, atestando que o produto foi elaborado em consonância com os direitos fundamentais. A pesar deste segundo mecanis mo mostrar-se, aparentemente, eficaz, o próprio autor reconhece que, em geral, a sociedade confia maisnas normas jurídicas do que em decisões voluntárias de consumidores. Sustenta que "... O ne rationale for the use of legal enactment over labelling is the potential ease of mislabelling products. The higher the cost of obtaining accurate information, the less desi rable is a market-based labeling strategy for obtaining desired labour standards ${ }^{\prime 28}$. Por outro lado, também não se pode confiar demais na regulação jurídica, posto que, por exemplo, muitos trabalhadores ainda têm negado o direito à negociação coletiva, embora a lei lhe garanta este direito.

Favorável a colocação dos direitos fundamentais no corpo da O M C , subordinados à cláusula social (social dumping dause) e sujeitos ao seu mecanismo de solução de conflitos, Alejandro Portessustenta queum passo fundamental para implementação efetiva destes direitos, seria tran fferir a sanção para as empresas, ao invés de aplicá-las aos governos, que, em decorrência, teriam reduzido os incentivos para atrair investimentos estrangeiros com base na inobservância de direitos mínimos. Transferir 0 ônus para as empresas seria uma forma de diminuir o debateentre países industrializados e países menos desenvolvidos.

\footnotetext{
${ }^{28}$ Todavia, como sustenta Ronnie Lipschutz, campanhas feitas com vistasao consumidor ou o chamado corporate market behaviour, não vão, necessariamente, resultar em mudanças políticas ou sociais. (Freeman 1994:314).
} 
Além desta medida, o autor sugere a adoção de uma outra política para fortalecimento do trabalho de acordo com o modelo atual de desenvolvimento: a promoção de pequenas e independentes empresas. Para ele, o desenvolvimento de high-tech pequenas empresas tem três conseqüências positivas para o fortalecimento dos direitos fundamentais no trabal ho. Primeiro, al ivia a pressão sobre salários e condições de trabalho; segundo, trabal hadores em novas empresas se beneficiam com as oportunidades de aprendizagem e treinamento; terceiro, o desenvolvimento de comunidades de pequenos produtores dá aos trabalhadores de grandes empresas a oportunidade de mudar para este novo setor. Em suas palavras "T he development of a dynamic small-scale sector can thus represent an efficient means to promote labour standards by giving workers the opportunity to make independent use of their energies and ingenuity" (Portes 1994).

\section{Conclusão}

A formatação de políticas públicas para implementação de direitos fundamentais no trabalho está no centro das discussões política e econômica internacionais e que separa o globo em países do norte e países do sul, variando suas opções entre as propostas neo-institucionalistas ou internacional istas do norte e as propostas culturalistas do sul. A polarização do debate pode ser retratada da seguinteforma: além de um conjunto mínimo de direitos fundamentais, a visão neoclássica sugere que 0 governo deveria deixar a implementação destes padrões para o mercado de trabalho livre. D eacordo com esta perspectiva, a el evação dos padrões prematuramenteintroduz distorções econômicas que retardam a criação de empregose renda. A visão neoinstitucional ista, ao contrário, vêtais padrões como instrumentosque podem influenciar o processo social de desenvolvimento deforma positiva ou negativa, dependendo de como os formadores de políticas públicas os aplicam ${ }^{29}$.

D esta forma, a adoção de direitos fundamentais como prioridade na implementação de políticas públicas no campo do trabalho deve sopesar a necessidade das empresas em ter suficienteflexibilidade para competir nos mercados globaise a necessidade do trabalhador em ter certa proteção social. Assim, há necessidade de atender às exigências internacionaise, ao mesmo tempo, elaborar legislação ou outro mecanismo de controle nacional para que, efetivamente, direitos fundamentais no trabal ho sejam cumpridos. $\mathrm{H}$ á, pois, necessidade de um procedimento democrático einstitu-

${ }^{29}$ Herzenberg \& Perez-Lopez, em nota de rodapé, citado por Amsden 1994. 
cionalizado, em cada país, para determinar os resultados econômicos através do comércio internacional contra o corrosivo impacto nos direitos fundamentais do traba$1 h 0^{30}$. Este procedimento só será efetivo e eficaz através da introdução de sanção comerciais aos países quenão cumpram ou não exijam o cumprimento, por partede empresas localizadas no seu território, de direitos fundamentais no trabalho, cuja premissa éa adoção de cláusulas sociais no âmbito dos acordos comerciaisinternacionais $^{31}$. D esta forma, estar-seá integrando políticas públicas nacionais às necessidades de ajuste à política econômica internacional ${ }^{32}$.

\section{Referências Bibliográficas}

ALBEN , E. "GATT and the Fair Wage: A historical Perspective on the Labor-Trade Link". In: Columbia Law Review. O utubro, 2001.

AM SD EN , A. H. ."M acro-sweating policiesand labour standards". In: SEN GEN BERGER, W., CAM PBELL, D. (O rg.). International Labor Standards and Economic Interdependence G eneva: International Institute for Labor Studies, 1994.

BASU, K. "Compacts, Conventions, and Codes: Initiatives for H igher International Labor Standards". In: Cornell International Law Journal. Vol. 34, 2001.

BH ALA, R. "Clarifying the Link". In: Columbia Journal of Transnational Law. Vol. 37, 1998.

\footnotetext{
${ }^{30}$ Segundo Dani Rodrik “... itisgoing to benational governments who areleft with theenforcement. Governments aremore and more feeling the pressure to compete". Businessand Human Rights, An Interdisciplinary Discussion Held at HLS, December 1997. Organizada pelo Human Rights Program HLS and the Lawyers Committee for Human Rights. Cambridge: Harvard Law School, 1999.

${ }^{31}$ Esta também éa opinião de Ronnie Lipschutz, assim manifestada: " ... we might expect that activist campaigns may, first, lead to theincorporation of labor standardsin intemational agreementsand discourseand, subsequently, become a growing focus of "interest group activities and public attention" within countries themselves. Under Those circumstances, sovereignty will not be challenged; rather, standards will be expected to observeand enforce such regulations as a matter of course". (Montgomery e Glazer 2002).

${ }^{32}$ Normalmente, políticas nacionais de trabalho são desenhadas mais como instrumentos de política social do que como instrumentos para assegurar eficiência na alocação e mobilidade da mão-de-obra e prover as necessidades de investimento em capital humano, segundo atesta J. Luis Guash, Labor Market Reform and Job Creation. TheWorld Bank. Washington: TheWorld Bank, 1999. O que se pretende, aqui, éreformular esta visão, buscandose eficiência e, ao mesmo tempo, progresso social. Por isto que a implementação de direitos fundamentais no trabalho deve estar combinada a um ajuste de política educacional, inclusive.
} 
BUSINESS and H uman Rights. An Interdisciplinary Discussion $\mathrm{H}$ eld at $\mathrm{HLS}$, D ecember, 1997". In: H uman Rights Program H LS and the Lawyers Committee for H uman Rights. Cambridge: H arvard Law School, 1999.

EH REN BERG, R. G. Labor marketsand Integrating National Economies. Washington: The Brookings Institutions, 1994.

FREEM AN , R. "A hard-headed look at labour standards". In: SEN GEN BERGER, W., CAM PBELL, D. (O rg.). International Labor Standards and Economic Interdependence. Geneva: International Institute for Labor Studies, 1994.

GOULD IV, W. B. "Labor Law for a Global Economy: The Uneasy Case for International Labor Standards". In: N ebraska Law Review. Vol. 80, 2001.

GUASH , J. L. Labor M arket Reform and Job Creation. The World Bank. Washington: The World Bank, 1999.

H OW ComplaintsWould BeH andled". In: N ew York Times, 14 deagosto de 1993.

LIPSCH UT Z, R. "D oing Well by D oing G ood?Transnational Regulatory C ampaigns, Social Activism, and Impacts on State Sovereignty". In: M O N T G O M ERY, J. D ., GLAZER, N. (O rg.). H ow Governments Respond: Sovereignty Under Challenge. N ew Brunswick e Londres: Transaction Publishers, 2002.

M O N T GO M ERY, J. D., G LAZER, N . (org.). H ow GovernmentsRespond: Sovereignty Under Challenge. N ew Brunswick e Londres: Transaction Publishers, 2002.

PO RTES, Alejandro. "By-passing the rules: The dialectics of labour standards and informalization in less developed countries". In: SEN GEN BERGER, W., CAM PBELL, D. (O rg.). International Labor Standards and Economic Interdependence. Geneva: International Institute for Labor Studies, 1994.

SEN GEN BERG ER, W., CAM PBELL, D . (O rg.). International Labor Standards and Economic Interdependence Geneva: International Institutefor Labor Studies, 1994. 
A Revista Cadernos PRO LAM /U SP é uma publicação periódica semestral, indexada, com Conselho Editorial de Arbitragem. 0 eixo temático é a integração da América Latina anal isand o sob quaisquer das seguintes dimensões: social, econômica, política, cultural e relações internacionais. Todo trabalho é submetido ao Conselho Editorial através de dupla arbitragem anônima.

\section{Normas de publicação}

1. As colaborações enviadas à Revista Cadernos PRO LAM /U SP deverão ser escritas em português, inglês, espanhol ou francês;

2. Extensão dos textos: Todo artigo deve ter no máximo 60.000 caracteres;

3. Forma de apresentação: Todo trabalho deve ser encaminhado à Redação em disquete acompanhado de duas cópias impressas 0 autor deve indicar sua filiação acadêmica e seu endereço para correspondência, que será publicado visando eventuais contatos por parte de outros pesquisadores. Todo artigo deverá estar acompanhado por um resumo (em português e inglês) de aproximadamente 10 linhas e por 5 palavraschave (em português, inglês ou espanhol).

4. Citações: D evem aparecer no corpo do texto, entre parênteses, indicando sobrenome do autor, data da publicação, página(s) citada(s). Por exemplo (Brown 1990: 70-75). No caso de diferentes títulos do mesmo autor no mesmo ano, o dado diferencial será uma letra após a data. Por exemplo: (Brown 1990a: 104-107).

Estas citações abreviadas enviam à bibliografia no final do artigo e que deve apresentar indicações completas, como segue:

Livro: SO BREN O M E, N ome do Autor. Título do Livro. Edição. Local de publicação, Editora, ano de publicação, quantidade de páginas.

Artigo de revistas: SO BREN O M E, N ome do Autor. "T ítulo do Artigo". Título do Periódico, N úmero do Volume, D ata do Volume, Páginas (inicial e final).

Artigo de coletâneas: SO BREN O M E, N ome do Autor. "Título do Trabalho", in SO BREN O M E, N ome do O rganizador. Título da Coletânea. Local de Publicação, Editora, D ata, Páginas (inicial e final).

5. N otas de Rodapé: podem ser utilizadas quando for preciso introduzir uma conceituação, uma discussão, uma digressão etc., que no corpo do texto quebraria a fluência do discurso. 
6. Ilustrações: devem ser utilizadas quando importantes para o entendimento do texto, pedindo-se que fotos, mapas, gráficos ou tabelas tenham boa resolução visual, de forma a permitir uma reprodução de qualidade.

7. Exemplares do Autor: serão enviados a cada autor quatro exemplares do número em que estiver publicada sua colaboração.

8. Restrições: todo material encaminhado à Revista C adernos PRO LAM /U SP deveser Inédito no Brasil e estar rigorosamente de acordo com as N ormas de Publicação, caso contrário, não serão apreciados. O s dados e conceitos são de exclusiva responsabilidade do autor.

\section{Endereço PRO LAM /U SP}

Rua do Anfiteatro, 181 - Colméia - Favo 1

CEP 05508-900 - Cidade Universitária - SP

Fone/Fax: 3091-3587 - 3091-3589 - 3815-0167

E-mail: prolam@usp.br

H ome-page: www.usp.br/prolam 